\title{
ADVANCES IN POWDER METALLURGY SOFT MAGNETIC COMPOSITE MATERIALS
}

\begin{abstract}
Powder metallurgy has grown with the expansion of various industry. Automotive industry had the most strong influence. Today, more than $90 \%$ of PM products are used in the transportation industry. Development of new materials such as magnetic materials is expected to meet the new trends of automotive industry, electric and hybrid vehicles.

Soft magnetic composites (SMC) are PM materials based on ferromagnetic powder particles covered by electric insulation layer. Concept of SMC's and PM technologies offer possibility to become faster, use higher frequencies, become smaller and denser, save more energy, achieving high permeability and lower core loss in high frequency region, which is required for soft magnetic materials. Investigation of correlations among compaction parameters, inner structure, magnetic and mechanical properties are presented.

Keywords: resin bonded SMC, soft magnetic ferrites, compaction, microwave sintering, magnetic and mechanical properties
\end{abstract}

\section{Introduction}

Soft magnetic composites (SMC) continue to find more and more electromagnetic applications in industrial practice. Gradual optimisation of electrical magnetic and mechanical properties promise to manufacture more energy efficient components. SMC are based on continuous insulating film between the ferromagnetic powder particles. Insulating film produces low total core loss, but it creates a non-conducting highly insulating boundary, thus preventing transfer of magnetic flux through adjacent powder particles [1-3]. Structure and properties of the interphase region among ferromagnetic particle is crucial for physical and mechanical properties of SMC. Researchers have been searching for fine soft magnetic materials with the high saturation magnetization, high permeability and low energy loss, which can be used in a wide frequency range and are especially useful at high frequencies [4-7]. A good insulation is generally required to minimize eddy current loss in SMC subjected from medium to high frequencies. To provide the permeability as high as possible, the amount of inter-particle insulation should be minimized and the ferromagnetic content maximized. Mechanical properties of SMC's are based on mechanical properties of secondary constituent, which is ordered to a network. Electric insulation constituent is a bond phase at the same time. Improving and optimisation of SMC material is complex and continuous process, which is influenced by technical possibilities, requirements of industrial practice and markets.

This contribution summarize relatively short period of SMC development of our research team, which involve low cost polymer bonded composites, hybrid organic-inorganic composites and SMC's with ceramics secondary constituent. Our investigation were focused on the materials suitable in middle and higher frequencies. Increased attention was paid to the interpretation of physical and mechanical properties changes in processes of preparation, compaction and heat treatment of the SMC materials.

\section{Experimental materials and methods}

\subsection{Experimental - polymer bonded SMC}

Powder iron ASC 100.29 supplied by Höganäs AB Sweden was used as ferromagnetic. Commercial phenol-formaldehyde resin supplied by ATM Gmbh (hereinafter referred as ATM) was used as insulation and bond phase. Powder Fe was mixed was mixed with acetone solution of ATM. Wet mixture was stirred while acetone evaporation to dry. Mixture was uniaxially cold pressed at $800 \mathrm{MPa}$ to the shape of cylinder (diameter $\mathrm{d}=10 \mathrm{~mm}$, height $\mathrm{h}=5 \mathrm{~mm})$, square prism $(4 \times 5 \times 20 \mathrm{~mm})$ and ring (outer diameter $\mathrm{d}_{\text {out }}=24 \mathrm{~mm}, \mathrm{~d}_{\text {inner }}=18 \mathrm{~mm}$, height $3 \mathrm{~mm}$ ). Green compacts were cured at $165^{\circ} \mathrm{C}$ in air for 15 minutes. Prepared SMC samples are referred as Fe/ATM.

Resole type phenol-formaldehyde resin (PFR) was prepared by poly-condensation reaction of phenol (99\%, Aldrich) and formaldehyde (37\% aq., Aldrich) with addition of ammonia (26\% aq., Aldrich). Basic PFR was modified by 3-glycidoxypropyltrimethoxysilane (GLYMO, 98\% Aldrich) and tetraethylortho-

\footnotetext{
* INSTITUTE OF MATERIALS RESEARCH OF SLOVAK ACADEMY OF SCIENCES, WATSONOVA 47, 04001 KOŠICE, SLOVAK REPUBLIC

** FACULTY OF SCIENCE, PAVOL JOZEF ŠAFÁRIK UNIVERSITY IN KOŠICE, KOŠICE, SLOVAK REPUBLIC

\# Corresponding author: rbures@saske.sk
} 
silicate (TEOS, 99\%, Merck) to prepare hybrid silica modified resin referred as PFRGT. PFRGT were prepared according to the procedure described in our previous work [8]. Another hybrid organic-inorganic resin was prepared using modification of PFR by boric acid (99.5\% Lachema) and it is referred as PFRB. Hybrid resins were coated on ferromagnetic powder particles of Fe ASC 100.29, FeSi ( $\mathrm{Fe}-3 \% \mathrm{Si}$ powder alloy, Höganäs AB Sweden, hereinafter referred as $\mathrm{FeSi}$ ) and Vitroperm (milled $\mathrm{Fe}_{73} \mathrm{Cu}_{1} \mathrm{Nb}_{3} \mathrm{Si}_{16} \mathrm{~B}_{7}$ amorphous stripe, Vacuumschmelze $\mathrm{GmbH}$ \& Co. KG, hereinafter referred as VPM). Identical wet mixing, coating, shaping and pressing methods were used as described above. Dissolving agent was tetrahydrofuran for PFRGT and ethanol for PFRB. Example of laboratory preparation of SMC based on inorganic modified resin is shown in Fig. 1. Time - temperature regime of curing cycle was characterized and optimized based on differential scanning calorimetry (Metler 2000C). All polymer bonded green compacts were cured in programmable laboratory heating chamber OF-2.

\subsection{Experimental - ceramic insulation based SMC}

Commercial $\mathrm{MgO}$ nano-powder (MTI Corp.) with narrow particle size distribution (mean size $30 \mathrm{~nm}$ ) was used to prepare $\mathrm{Fe} / \mathrm{MgO}$ composite. $\mathrm{MgO}$ ratio varied from $1 \mathrm{wt} . \%$ to 13.85 wt. \%. Mixtures of micro- and nano-powder were homogenized by resonant acoustic method in LabRAM mixer. Green compacts were pressed uniaxially at pressing pressure $600 \mathrm{MPa}$. Laboratory chamber muffle furnace was used to conventional sintering of $\mathrm{Fe} / \mathrm{MgO}$ in air atmosphere. Microwave sintering (MWS) at frequency $2.45 \mathrm{GHz}$ were realized in single mode cavity (diameter $\mathrm{d}=30 \mathrm{~mm}$, height $80 \mathrm{~mm}$ ) equipped by impedance analyser and multi-mode MW furnace Hamilab V3000 (Synotherm Corp.). Temperature was measured by IR pyrometer optris in single mode equipment or Raytek in Hamilab furnace respectively.

$\mathrm{MnZn}$ ferrite nano-powder was prepared from nitrate precursors: $\mathrm{Mn}\left(\mathrm{NO}_{3}\right)_{2} \cdot 4 \mathrm{H}_{2} \mathrm{O}\left(99 \%\right.$, Acros Organic), $\mathrm{Zn}\left(\mathrm{NO}_{3}\right)_{2} \cdot 4 \mathrm{H}_{2} \mathrm{O}$ (98\%, Acros Organic), $\mathrm{Fe}\left(\mathrm{NO}_{3}\right)_{2}(99+\%$, Acros Organic) and $\mathrm{C}_{6} \mathrm{H}_{8} \mathrm{O}_{7} \cdot \mathrm{H}_{2} \mathrm{O}$ (99.8\% CentralChem) by sol-gel process followed by auto-combustion as it is described in previous work [9]. Agglomerated prepared cubic ferrite spinel $\mathrm{Mn}_{0.8} \mathrm{Zn}_{0.2} \mathrm{Fe}_{2} \mathrm{O}_{4}$ particles were disintegrated by short milling in vibrating ball mill (Laarmann). MnZn ferrite (3 wt.\%) powder were dry mixed with FeSi powder. The mixture was homogenized by resonant acoustic method. Uniaxial cold pressing at $600 \mathrm{MPa}$ was applied to prepare green compacts.

All green compact samples were pressed using precise programmable press LabTest 5.600 ZL (Labortech s.r.o.) with capacity of $60 \mathrm{~T}$. Powder particle size was measured by laser diffraction technique using Mastersizer 2000E. The density of prepared samples were determined by the He pycnometer (AccuPyc II 1340, Micromeritics).

Mechanical properties were evaluated by measurement of transverse rupture strength (TRS) and Vickers macro-hardness (HV). TRS was measured by MPIF 41 using prism shape sample. HV was measured by MPIF 43 using cylindrical shape samples. Universal testing machines Tiratest 2100 and hardness tester Tukon 1102 were used. Young modulus (E) was measured by impulse excitation technique using Buzz-o-Sonic equipment using prism shape samples. Microstructure of the composites was observed using optical microscopy (Nikon SMZ-18, Eclipse MA200) and electron microscopy (Jeol JSM 7000F, Tescan Wega3).

The DC hysteresis loops were measured by a fluxmeter based hysteresis graph and $\mathrm{AC}$ hysteresis loops were measured by an AC hysteresis graph Model MATS-2010SA. The ring shape samples with toroidal coil were used. The specific electrical resistivity of the cylinder shape composites were measured by four point probe method according to van der Pauw.

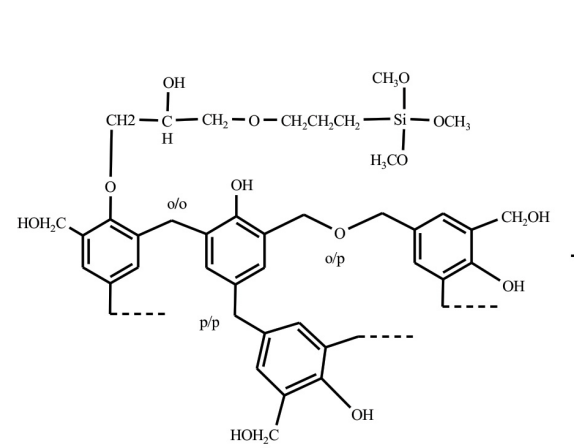

Phenolic resin with TEOS and GLYMO bridge

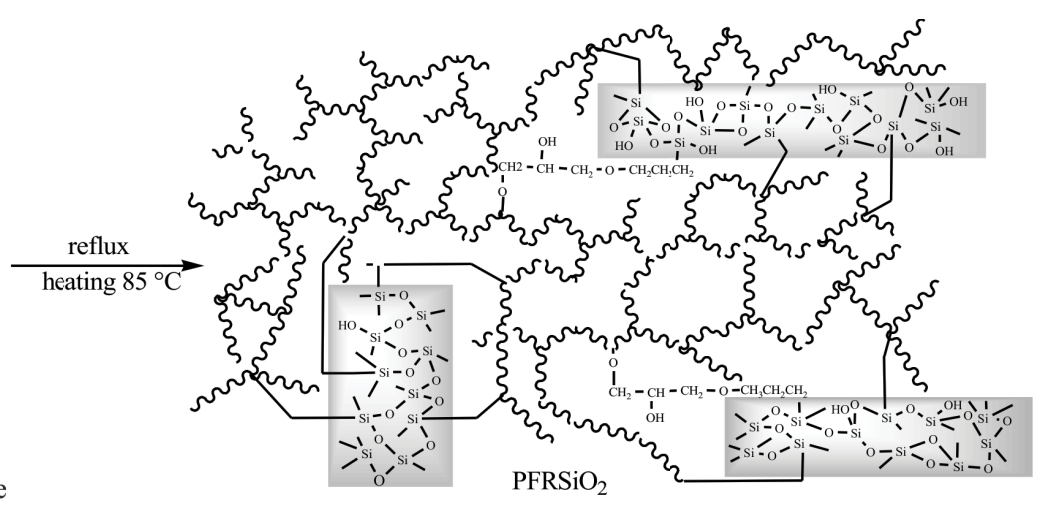

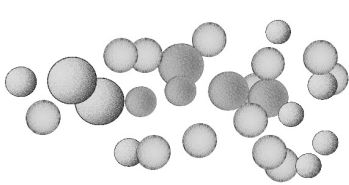

feromagnetic powder

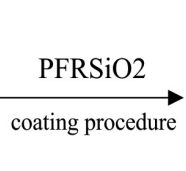

$\rightarrow$

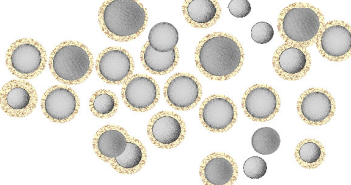

core - shell

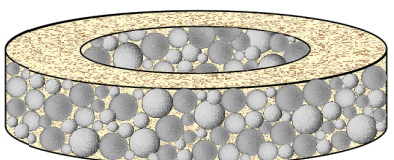

thoroidal shape sample

Fig. 1. Scheme of preparation of the SMC based on Ferromagnetic/PFRGT 


\section{Results and discussion}

\subsection{Results - polymer bonded SMC}

SEM morphology of powder ferromagnetic is documented in Fig. 2. Microstructure of polymer bonded SMC is shown in Fig. 3. Resin created continuous insulation and bond network in the composite. Thickness and distribution of polymer phase were influenced by resin content ratio, pressing pressure and by ferromagnetic morphology. Mechanical properties (Table 1) of the composite correlates with mechanical properties of applied resin after curing. Resin content ratio strongly influence resistiv- ity and permeability of SMC's as well as magnetic losses. Eddy current losses are low due to very good electric insulation of ferromagnetic particles, but total losses are higher due to higher hysteresis losses (Figs. 4,6). Suitable mechanical strength was achieved using at least $3 \mathrm{wt} . \%$ of resin content ratio, which induced lower saturation flux density and higher hysteresis losses. Temperature of degradation of the resins is lower than stress relief temperature of applied ferromagnetic, that is why the coercivity of resin bonded SMC's were higher also. Higher mechanical strength and higher resistivity are often accompanied by lower magnetic properties and vice versa as in the case of VPM/ATM composite and VPM/PFRGT it is.

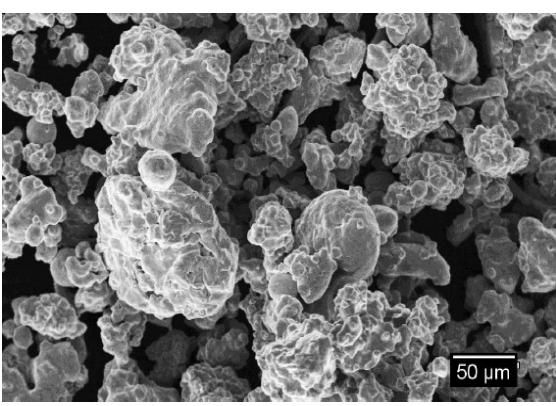

ASC 100.29

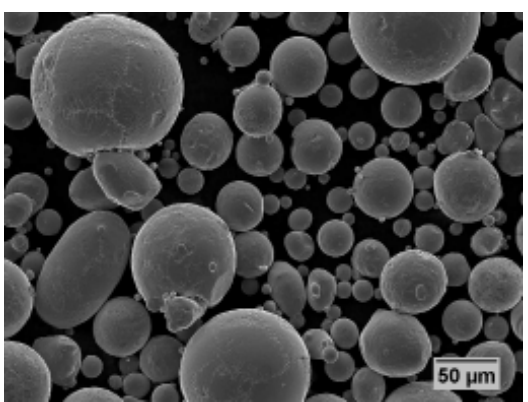

$\mathrm{Fe} 3 \mathrm{Si}$

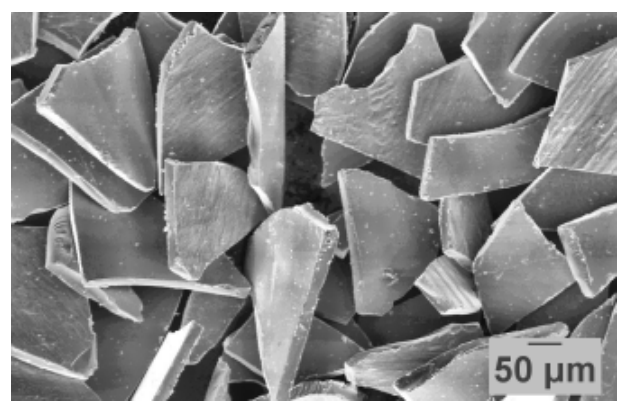

Vitroperm

Fig. 2. SEM morphology of ferromagnetic powders

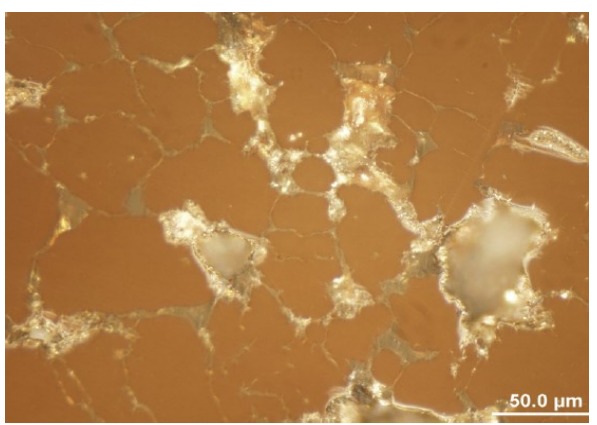

$\mathrm{Fe} / 10 \mathrm{ATM}$

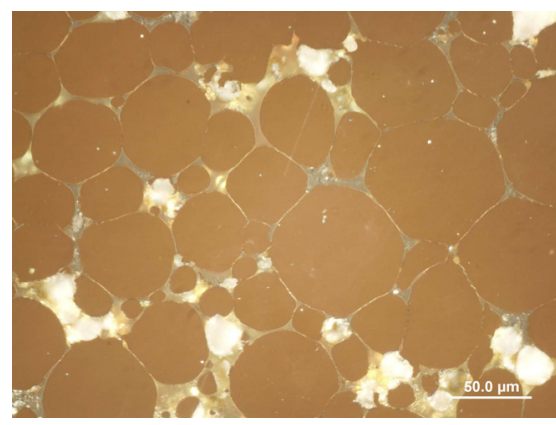

Fe3Si/3PFRGT

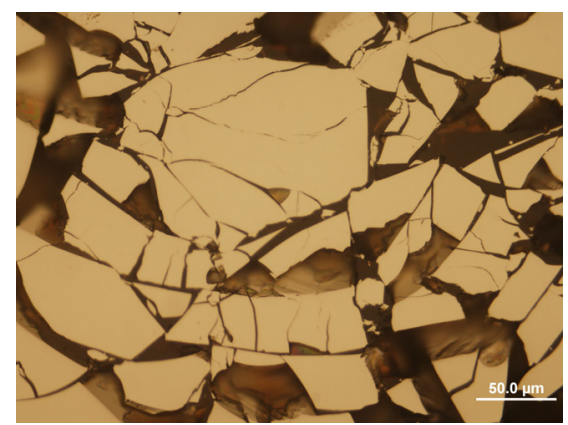

Vitroperm/3PFRGT

Fig. 3. Microstructure of SMC's, polarized light optical microscopy

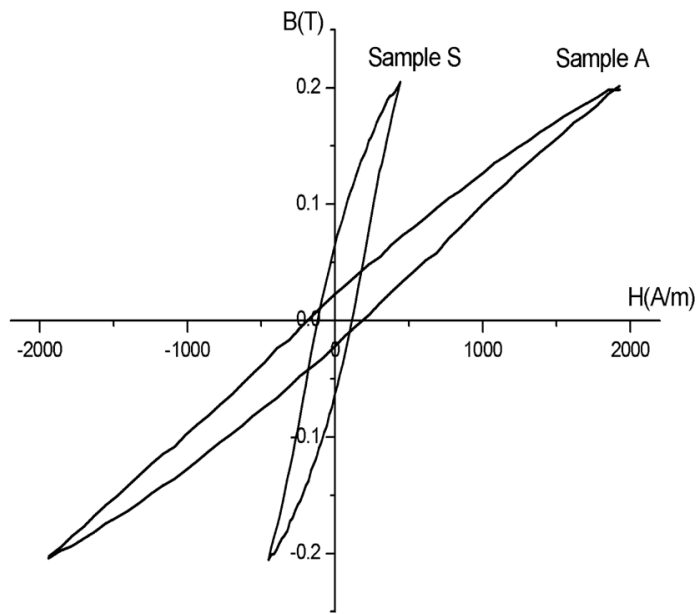

Fig. 4. Hysteresis loop of Fe/10ATM SMC (A) and reference Somaloy $\mathrm{SMC}(\mathrm{S})$

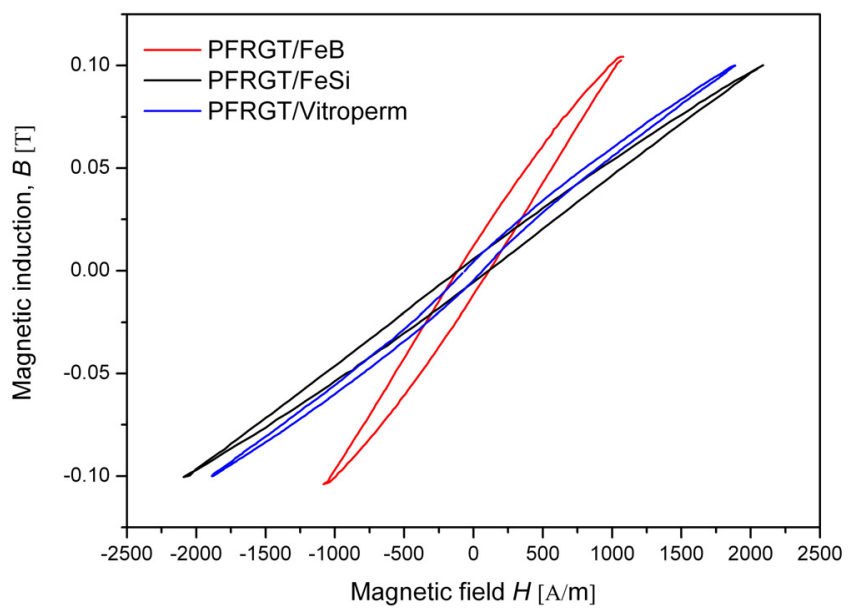

Fig. 5. Hysteresis loops of SMC's based on PFRGT resin 


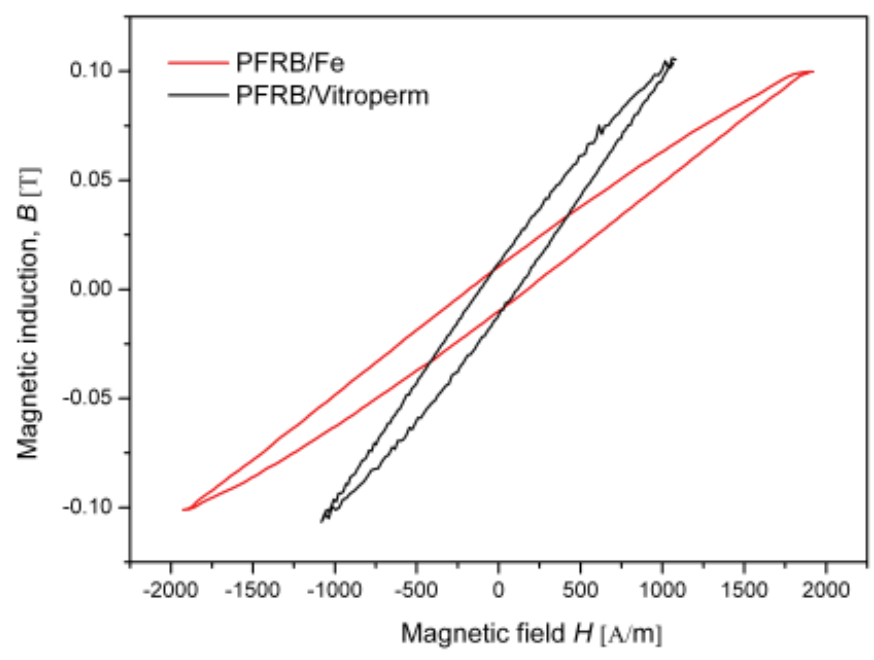

Fig. 6. Hysteresis loops of SMC's based on PFRB resin

TABLE 1

Experimental composition and properties of resin bonded SMC's

\begin{tabular}{|c|c|c|c|c|c|}
\hline \multirow[b]{2}{*}{ Samples } & \multicolumn{2}{|c|}{$\begin{array}{c}\text { Mechanical } \\
\text { properties }\end{array}$} & \multicolumn{3}{|c|}{ Magnetic properties } \\
\hline & HV & $\begin{array}{c}\text { TRS } \\
\text { (MPa) }\end{array}$ & $\begin{array}{c}\mathrm{R} \\
(\mathrm{m} \Omega . \mathrm{m})\end{array}$ & $\begin{array}{l}\text { Total } \\
\text { losses } \\
\left(\mathrm{J} / \mathbf{m}^{3}\right)\end{array}$ & $\begin{array}{l}\text { Coercivity } \\
\mathbf{H}_{\mathbf{c}}\left(\mathbf{A}^{-m^{-1}}\right)\end{array}$ \\
\hline $\mathrm{Fe} / 10 \mathrm{ATM}$ & 62 & 45 & 505 & 121 & - \\
\hline VPM/10ATM & 44 & 33 & 830 & 15 & - \\
\hline Fe/15Epoxy [10] & 44 & 35 & - & - & 228 \\
\hline $\mathrm{Fe} / 3$ PFRB & 280 & 105 & $0.9 \times 10^{5}$ & 230 & $110-180$ \\
\hline Fe/3PFRGT & 140 & 117 & $1.1 \times 10^{5}$ & 210 & 203 \\
\hline VPM/4PFRGT & 92 & - & $2.1 \times 10^{5}$ & & $60-70$ \\
\hline FeSi/4PFRGT & 140 & 97 & $2 \times 10^{6}$ & & $100-200$ \\
\hline
\end{tabular}

The properties of resin bonded SMC based on the PFRGT and the PFRB are tunable by precise setting of temperature-time regime of curing cycle. Curing cycle driven mechanical and magnetic properties of PFRB based SMC were basic idea of submitted patent application [11].

Evidently, functional properties of resin bonded composites are driven by properties of the resin phase in inter-particle region among ferromagnetic particles as it is documented by MFM in Fig. 7. The investigation of SMC's interphase regions and motivation to apply high temperature heat treatment/sintering led to study of ceramic based SMC's.

\subsection{Results - ceramic based SMC}

Investigation of the $\mathrm{Fe} / \mathrm{MgO}$ composites in wide range of $\mathrm{MgO}$ content ratio from 1 up to $13.85 \mathrm{wt} . \%$ shows the possibility to modify the design and properties of ceramic interphase region by sintering kinetics. Formation of the magnesium ferrite spinnel in $\mathrm{MgO}$ interphase region is driven by time of the sintering and by initial content of $\mathrm{MgO}$ at the same time. MWS sintering process is significantly shorter in comparison with conventional sintering. The $\mathrm{Fe} / \mathrm{MgO}$ composite $\mathrm{MW}$ sintered for 10 minutes in single mode cavity achieved the same properties as the sample conventionally sintered for 60 minutes (Figs. 8,9). Higher content of magnesium ferrite spinel and lower content ratio of residual $\mathrm{MgO}$ improve the flexural strength, elasticity and coercivity of the $\mathrm{Fe} / \mathrm{MgO} \mathrm{SMC}$ as it is shown in Table 2. Microstructure and morphology of the FeSi/MnZn ferrite composite was strongly influenced by applied sintering method, mainly in ferrite regions among the FeSi particles (Figs. 10,11). The influence of these morphology changes on magnetic and mechanical properties is a subject of intensive investigation of our research team at the present. There is indication based on MFM observation, that positive influence on a magnetic flux in the FeSi inter-particle region could be expected (Fig. 12).
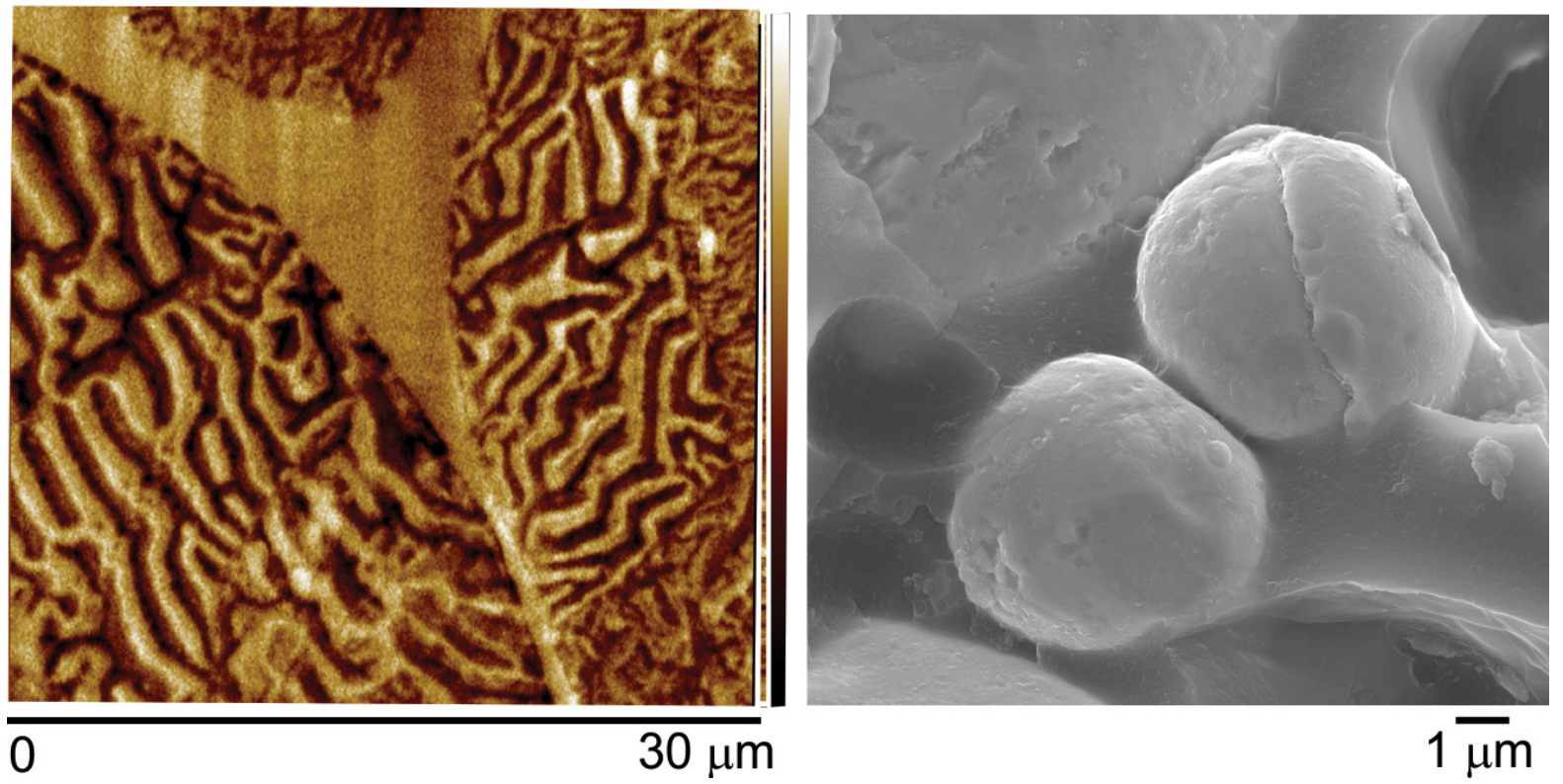

Fig. 7. Magnetic force microscopy of interparticle region of cured FeSi/3PFRGT SMC (left) and Fe3Si particles with PFRGT coating layer (right) 


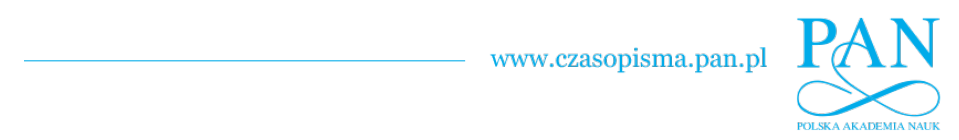

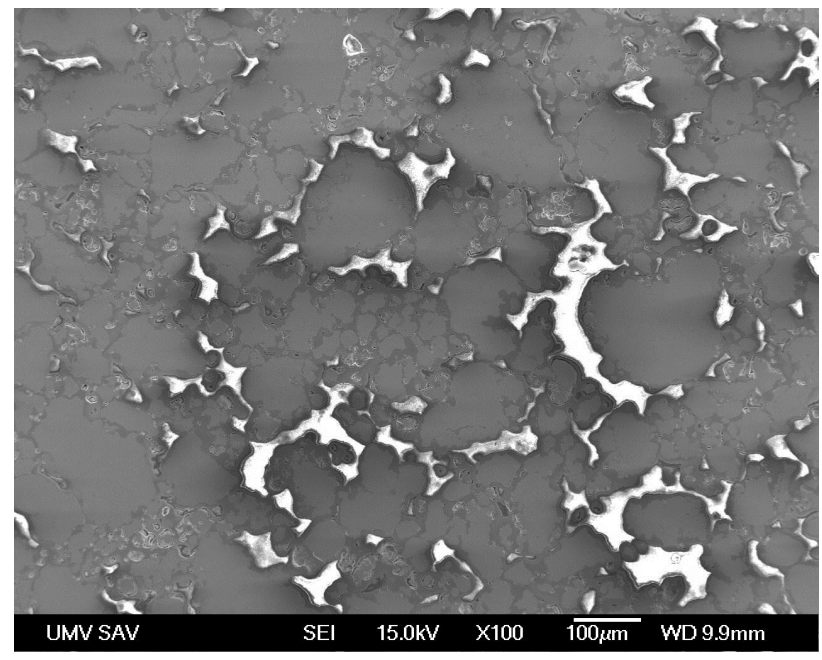

Fig. 8. Conventional sintered $\mathrm{Fe} / 13.85 \mathrm{MgO}, 600^{\circ} \mathrm{C}, 60 \mathrm{~min}$, air

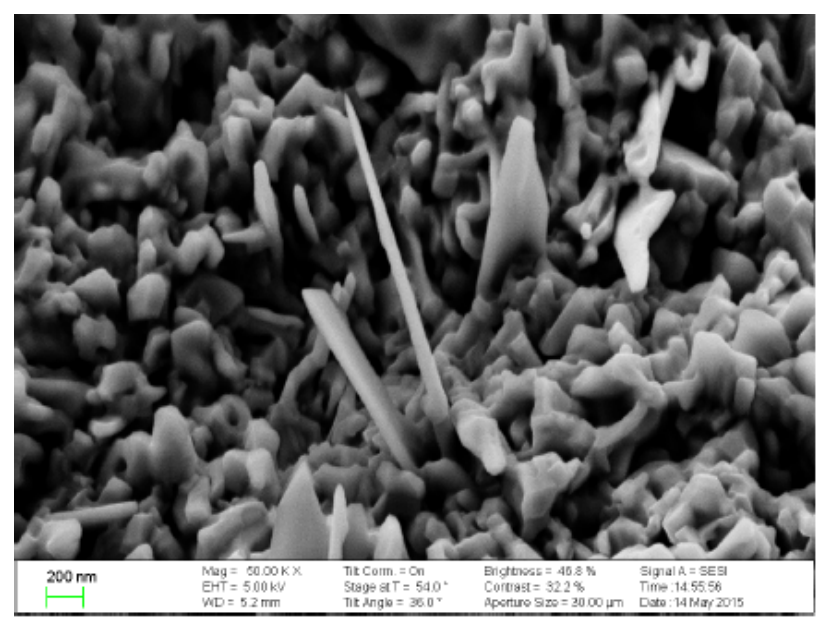

Fig. 10. Conventional sintered $\mathrm{FeSi} / 3 \mathrm{Mn} 0.8 \mathrm{Zn} 0.2 \mathrm{Fe} 2 \mathrm{O} 4,800^{\circ} \mathrm{C}$, $60 \mathrm{~min}$, air

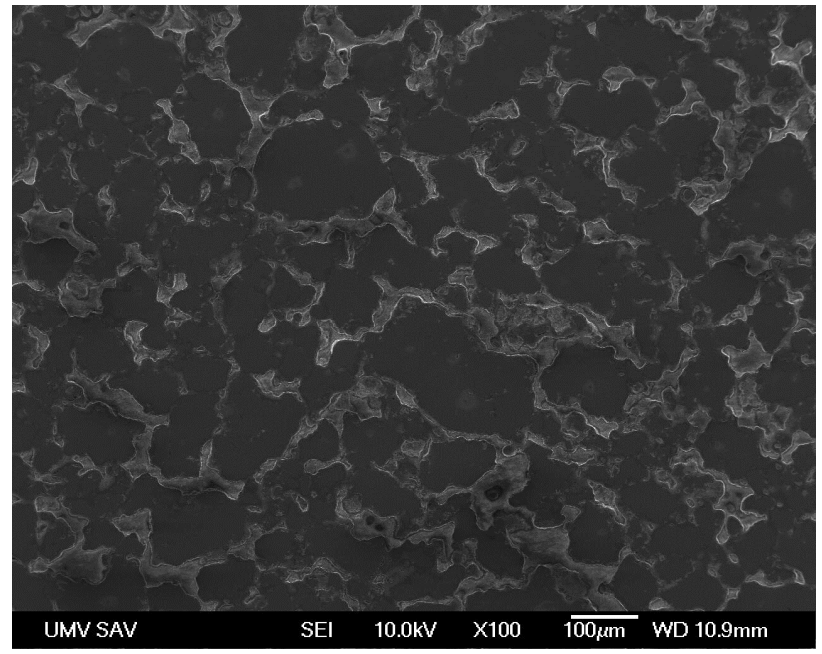

Fig. 9 Microwave sintered Fe/13.85MgO, $600^{\circ} \mathrm{C}, 10 \mathrm{~min}$, air

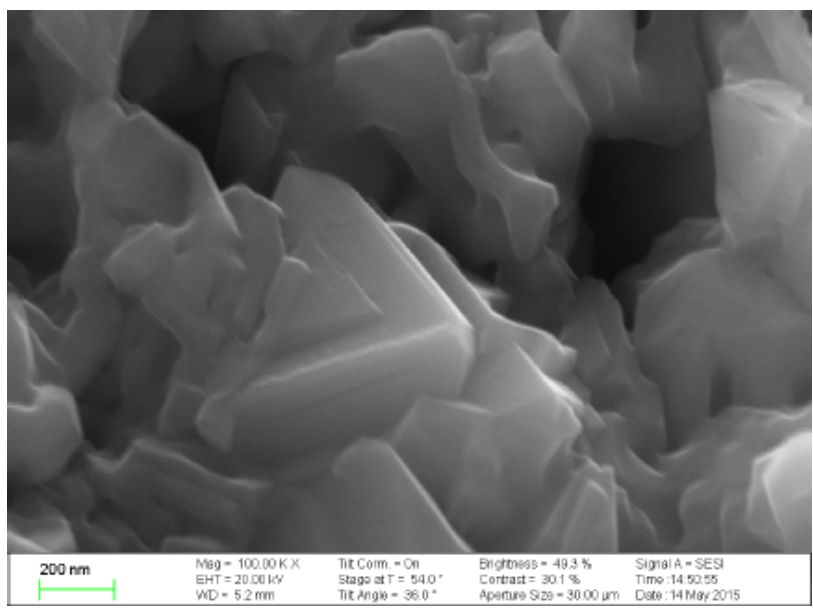

Fig. 11. Microwave sintered FeSi/3Mn0.8Zn0.2Fe2O4, $800^{\circ} \mathrm{C}, 15 \mathrm{~min}$, air
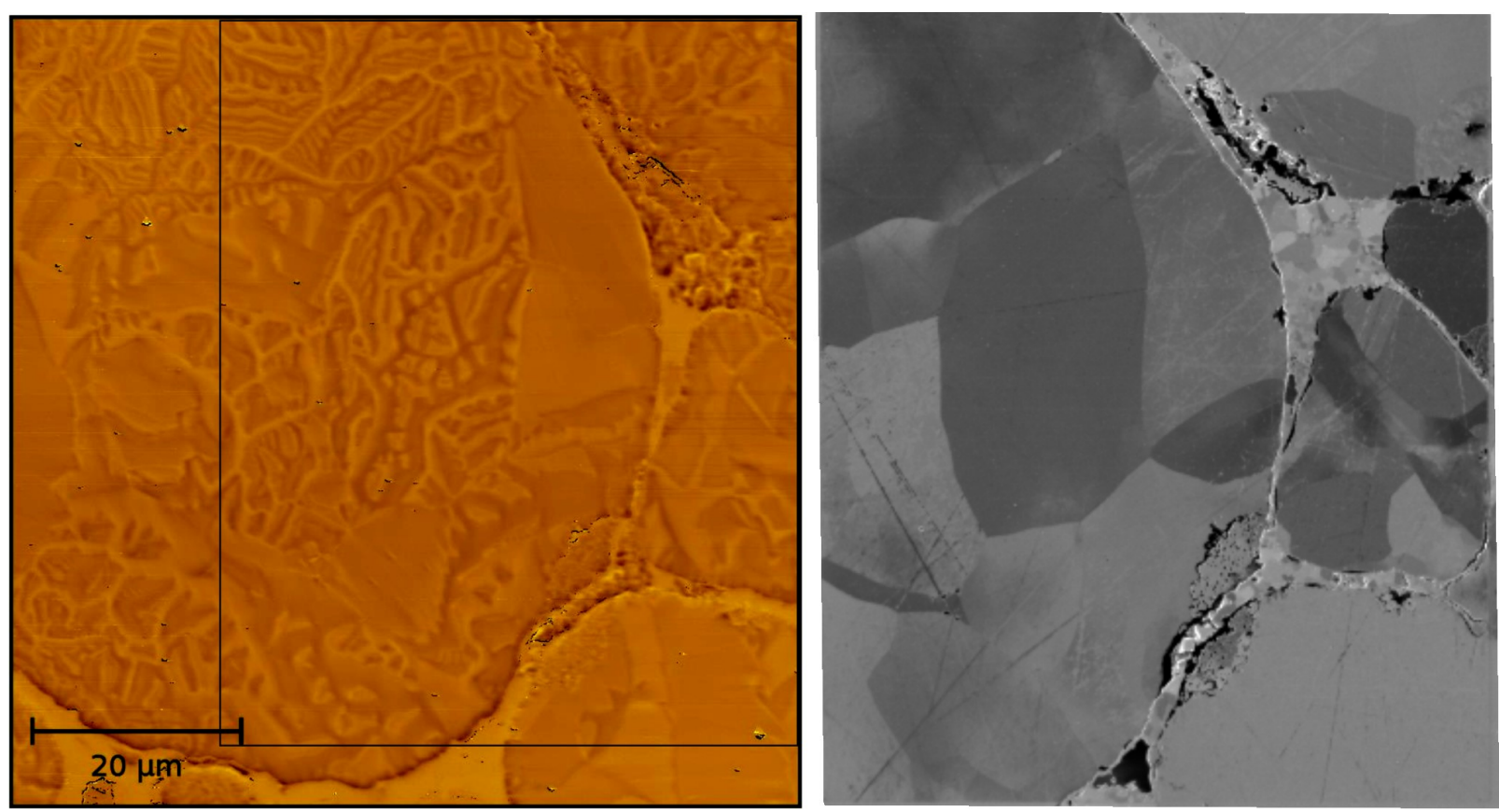

Fig. 12. Magnetic force microscopy and SEM image of interparticle region of microwave sintered $\mathrm{FeSi} / 3 \mathrm{Mn} 0.8 \mathrm{Zn} 0.2 \mathrm{Fe} 2 \mathrm{O} 4 \mathrm{SMC}$ 
TABLE 2 One of the perspective ways how to improve the functional

Experimental composition and properties of MWS ceramic based SMC's

\begin{tabular}{|c|c|c|c|c|c|}
\hline \hline \multirow{2}{*}{ Samples } & \multicolumn{2}{|c|}{$\begin{array}{c}\text { Mechanical } \\
\text { properties }\end{array}$} & \multicolumn{3}{|c|}{ Magnetic properties } \\
\cline { 2 - 6 } & $\begin{array}{c}\text { TRS } \\
\text { (MPa) }\end{array}$ & $\begin{array}{c}\text { E } \\
\text { (GPa) }\end{array}$ & $\begin{array}{c}\text { Coer- } \\
\text { civity } \\
\text { (A.m } \mathbf{- 1}^{-1}\end{array}$ & $\begin{array}{c}\text { Real part } \\
\text { of complex } \\
\text { permeabil- } \\
\text { ity (-) }\end{array}$ & $\begin{array}{c}\text { Total loses } \\
\text { at 40Hz } \\
\left(\mathbf{J . m}^{-3}\right)\end{array}$ \\
\hline $\mathrm{Fe} / 1 \mathrm{MgO}$ & 112 & 113 & 300 & 9 & \\
\hline $\mathrm{Fe} / 2 \mathrm{MgO}$ & 106 & 107 & 292 & 10 & \\
\hline $\mathrm{Fe} / 3 \mathrm{MgO}$ & 79 & 105 & 285 & 11 & \\
\hline $\mathrm{Fe} / 5 \mathrm{MgO}$ & 65 & 90 & 295 & 12 & \\
\hline $\mathrm{Fe} / 10 \mathrm{MgO}$ & 38 & 48 & 391 & 17 & \\
\hline $\mathrm{Fe} / 13.85 \mathrm{MgO}$ & 35 & 48 & 824 & 14 & 83 \\
\hline $\begin{array}{c}\mathrm{FeSi} / \\
3 \mathrm{Mn}_{0.8} \mathrm{Zn}_{0.2} \\
\mathrm{Fe}_{2} \mathrm{O}_{4}\end{array}$ & 145 & 121 & 424 & 38 & 57 \\
\hline
\end{tabular}

\section{Conclusions}

The development of the soft magnetic composites from polymer bonded composites to SMC's with ceramics insulation is presented in the paper. Low cost, relatively good mechanical and functional properties are advantages of polymer and hybrid organic-inorganic based SMC. Further improvement of this composites is limited by impossibility to use a heat treatment at higher temperature to relief a residual stresses in cold compacted ferromagnetic. Reduction of the resin content is restricted by suitable mechanical strength of the SMC.

Applicability of high temperature sintering and heat treatment is advantage of the SMC's with ceramics insulation constituent. Conventional and advanced sintering technologies gives more possibility to design of inner structure of the composites. properties of the SMC is microstructural design optimisation of micro ferromagnetic - nano ferrimagnetic composites. Mechanical brittleness and insufficient magnetic flux density limit of wider range of application of this soft magnetic composites.

\section{Acknowledgements}

This work was supported by the Scientific Grant Agency of the Ministry of Education, Science, Research and Sport of the Slovak Republic and the Slovak Academy of Sciences, project No. VEGA 2/0185/15. This work was realized within the frame of the project „Advanced technology of preparing of micro-composite materials for electrotechnics", which is supported by the Operational Program "Research and Development" financed through European Regional Development Fund ITMS:26220220105.

\section{REFERENCES}

[1] http://www.gkn.com/hoeganaes/Pages/default.aspx

[2] L. Svensson et al., JMMM 324, 2717 (2012).

[3] T. Ueno et al., Sei. Tech. Rev. 82, 9 (2016).

[4] S. Wu et al., JMMM 324, 3899 (2012).

[5] Y. Pittini-Yamada et. al., Acta Mater. 59, 4291 (2011).

[6] P. Kollár et al., JMMM 388, 76 (2015).

[7] P. Kollár et al., JMMM 353, 65 (2014).

[8] M. Strečková et al., Mater. Lett. 101, 37 (2013).

[9] M. Strečková et al., Advances Mater. Sci. Engineering 2015, (2015).

[10] H. Shokrollahi, K. Janghorban, Mat. Sci. Eng. B. 134, 41 (2006).

[11] R. Bureš, et al., Patent proposal No. PP 0009572013. ÚPV SR, (2013). 